\title{
Pseudomonas fluorescens: A Proficient Plant Growth Promoting Rhizobacteria Isolated from Organic Farm
}

\author{
Harshada S. Kitey" and Vijay N. Charde \\ Department of Microbiology, Taywade College, Koradi, Nagpur, 441111, MS, India \\ *Corresponding author
}

\section{A B S T R A C T}

Keywords

Pseudomonas

fluorescens,

OrgS63, OrgS49,

Fusarium

oxysporum

\section{Article Info}

Accepted:

17 October 2019

Available Online:

10 November 2019
In the present study, strains of Pseudomonas fluorescens designated as OrgS63 and OrgS49 isolated from soybean rhizosphere of an organic farm. Siderophore production was detected by using modified Fiss Minimal medium and estimation was done by CAS assay. Both the strains were found to produce good amount of siderophores. These Pseudomonas strains were screened for their other plant growth promoting traits like IAA production, production of Ammonia, HCN production, Phosphate solubilization and antifungal activity. OrgS63 was the most efficient phosphate solubilizer on NBRIP plates with a solubilization index of 6.10. In liquid NBRIP medium, significantly higher Phosphate solubilization was recorded for both the strains OrgS63 and OrgS49 (440 and $450 \mu \mathrm{g} / \mathrm{ml}$ ) after 5 days of incubation. Both the strains OrgS63 $(90.00 \%)$ and OrgS49 $(90.44 \%)$ has shown high \% inhibition against Fusarium oxysporum. These isolates also showed positive results for Indole 3-acetic acid (IAA), ammonia production, hydrogen cyanide ( $\mathrm{HCN})$ production and ammonia production. Thus, the present study concludes that these Siderophore producing Pseudomonas fluorescens strains could serve as a proficient Plant growth promoting Rhizobacterial inoculants for improving the cropping systems and enhancing metal remediation of polluted environments.

\section{Introduction}

Due to excessive use of chemical fertilizers in agricultural field, the soil loses the microbial activity. It is reported that Organic applications in agricultural farms increases the microbial activity drastically as compare to soil with chemical fertilizers [3]. In rhizosphere, siderophore producing Pseudomonas plays a central role in improvement of the plant development. These bacteria act as biocontrol agent by limiting iron nutrition to the pathogen. Many bacteria synthesize siderophore that has an high affinity for ferric iron, resulting in ferricsiderophore complex which is transported into the cell and thus facilitates iron uptake under low iron condition making unavailable to the other organisms and restrict the growth of deleterious bacteria and fungi at the root [1]. 
Siderophore producing bacteria showing metal resistant property is useful in bioremediation of metal polluted iron depleted soils [2].

Pseudomonas sp. is abundant in agricultural soils which make them perfect suitable as Plant growth promoting Rhizobacteria (PGPR) [4].

The present study was conducted to isolate and check plant growth promoting along with metal resistant abilities of Rhizobacteria from an Organic Farm.

\section{Materials and Methods}

\section{Bacterial strains}

Strains of Pseudomonas fluorescens designated as OrgS63 and OrgS49 was isolated from soybean (Glycine max L) rhizosphere of an organic farm.

The pure culture isolates were maintained on modified King's B agar(for 1 litre, proteose peptone, $20 \mathrm{gm} ; \mathrm{KH}_{2} \mathrm{PO}_{4}, 1.0 \mathrm{gm} ; \mathrm{MgSO}_{4}$, 0.4gm; Glycerol, 8ml; agar $20 \mathrm{gm}$ ) slants at $4^{\circ} \mathrm{C}$ and used for further studies.

\section{Detection of siderophore production}

Both the strains were grown overnight at $28^{\circ} \mathrm{C}$ in modified King's B Broth. The bacterial isolates were spot inoculated on Chrome Azurol S Agar plates and visualized for the appearance of pink halo zones against blue background after $72 \mathrm{hrs}$ of incubation at 28 ${ }^{\circ} \mathrm{C}[4]$.

\section{Plant growth promoting traits}

\section{Phosphate solubilization}

Phosphate solubilization by the strains was detected qualitatively on NBRIP agar plates and also measured quantitatively by using
NBRIP medium and solubilization index was calculated by using the following formula (Edi-Premono et al., 1996) [5].

$\mathrm{SI}=\underline{\text { Colony diameter }+ \text { Halozone diameter }}$ Colony diameter

\section{HCN production}

HCN production by the isolates was detected by the method of Baker and Schipper, 1987 [6].

\section{IAA production}

Indole acetic acid production by the isolates was quantitatively measured by the method given by Gordon and Weber (1951) [6].

\section{Ammonia production}

Ammonia production was detected by adding $1 \mathrm{ml}$ Nessler's reagent to a $72 \mathrm{~h}$ old culture grown in peptone broth) and recorded the presence of the deep yellow to orange colour [6].

\section{Antifungal activity}

For determining the Antifungal activity, Pseudomonas cultures was streaked on Potato Dextrose Agar $1.5 \mathrm{~cm}$ from the edge of the each plate along with fungus (Fusarium oxysporum) and were incubated at $28 \pm 2{ }^{\circ} \mathrm{C}$. Each test was replicated three times. Radial growth was measured and percent of radial growth inhibition was calculated [6].

Percent of radial growth inhibition $=(\mathrm{R} 1-\mathrm{R} 2 / \mathrm{R} 1) \times 100$

R1 = Radial growth of Fusarium oxysporum in control plate

R2 = Radial growth of Fusarium oxysporum interacting with antagonistic bacteria 


\section{Metal resistant ability}

The isolates were tested by agar dilution method for their resistance to heavy metals (Co and $\mathrm{Zn}$ ). Metal concentration ranging from 25 to $200 \mu \mathrm{g} / \mathrm{ml}$ were inoculated with overnight grown culture on Nutrient agar plates. Metal Resistant ability was observed after incubating the plates for 24 to 48 hours[7].

Effect of Pseudomonas fluorescens on seedling growth of Glycine max L (Soybean seeds)

The strains were subjected for their efficacy on seed germination and seedling growth of Soybean seeds (variety JS 335). The bacterial suspension were prepared and tested for their plant growth promoting efficiency, which was carried out by the standard paper Roll towel method (ISTA, 1993).

The soybean seeds were mixed with bacterial suspension. Plant growth promotion of soybean seedling was assessed using Vigour Index (Baki and Anderson, 1973) [8].

Vigour index $=$ Percent Germination $\mathrm{X}$ seedling length (shoot length + root length)

\section{Result and Discussion}

The strains isolated in this study were Gram negative short rods and colonies produced fluorescence under uv light. On CAS Agar plates they produced pink color halo zones and tested positive for Siderophore production. These Pseudomonas strains were screened for their other plant growth promoting traits like IAA production, production of Ammonia, HCN production, Phosphate solubilization and antifungal activity. OrGS63 was the most efficient phosphate solubilizer on NBRIP plates with a solubilization index (SI) of 6.10 whereas OrGS49 has SI 5.16 (showing clear halo zone of solubilization $31 \mathrm{~mm}$ and $24 \mathrm{~mm}$ respectively)In liquid NBRIP medium, significantly higher Phosphate solubilization was recorded for isolates OrGS63 and OrGS49 (440 and $450 \mu \mathrm{g} / \mathrm{ml}$ ) after 5 days of incubation

Both the strains OrgS63 (90.00\%) and OrgS49 (90.44\%) has shown high \% inhibition against Fusarium oxysporum. Positive results indicate that HCN production by rhizospheric microbes has been proposed as a possible defense mechanism against soil borne plant pathogens (Walia et al., 2013) (Fig. 1-9; Table 1 and 2).

\section{Isolate OrGS63 and OrGS49}

Isolate OrGS63 and OrGS49 also shows positive results for ammonia production and revealed significant level of Indole acetic acid (IAA) $19.00 \mu \mathrm{g} / \mathrm{ml}$ and $16.4 \mu \mathrm{g} / \mathrm{ml}$.

Both the strains shows resistance to Heavy metals such as Co and Zn. OrGS63 and OrGS49 shows resistance in all concentration ( 25 to $200 \mu \mathrm{g} / \mathrm{ml}$ ) of both the metal.

OrgS63 and OrGS49 showed higher SVI 2349 and 2002 after $8^{\text {th }}$ day of germination period. The results revealed that seed treatment with Pseudomonas strains improved seed germination and seedling vigour index over the control (SVI 787).

Thus, the present study concludes that these Siderophore producing Pseudomonas fluorescens strains may serve as a proficient Plant growth promoting Rhizobacterial inoculants for improving the cropping systems and enhancing metal remediation of polluted environments. 
Table.1 Plant growth promoting characteristics of both the strains

\begin{tabular}{|c|c|c|c|c|}
\hline \multirow{2}{*}{$\begin{array}{c}\text { Pseudomonas } \\
\text { Strains }\end{array}$} & \multicolumn{4}{|c|}{ Plant growth promoting characteristics } \\
\cline { 2 - 5 } & $\begin{array}{c}\text { Phosphate } \\
\text { solubilization }\end{array}$ & HCN Production & IAA Production & $\begin{array}{c}\text { Ammonia } \\
\text { production }\end{array}$ \\
\hline OrGS63 & + & + & + & + \\
\hline OrGS49 & + & + & + & + \\
\hline
\end{tabular}

Table.2 Efficacy of Pseudomonas strains on seedling growth and SVI

\begin{tabular}{|c|c|c|c|c|c|c|c|}
\hline \multirow[t]{2}{*}{ S.N } & \multirow[t]{2}{*}{ PSB Isolates } & \multicolumn{2}{|c|}{ On $2^{\text {nd }}$ day } & \multicolumn{2}{|c|}{ On $4^{\text {th }}$ day } & \multicolumn{2}{|c|}{ On $8^{\text {th }}$ day } \\
\hline & & $\begin{array}{l}\text { Seedling } \\
\text { length }\end{array}$ & $\begin{array}{c}\text { Seedling } \\
\text { Vigour } \\
\text { Index }(\mathrm{SVI})\end{array}$ & $\begin{array}{l}\text { Seedling } \\
\text { length }\end{array}$ & $\begin{array}{c}\text { Seedling } \\
\text { Vigour } \\
\text { Index }(\mathrm{SVI})\end{array}$ & $\begin{array}{l}\text { Seedling } \\
\text { length }\end{array}$ & $\begin{array}{c}\text { Seedling } \\
\text { Vigour } \\
\text { Index(SVI) }\end{array}$ \\
\hline 1 & OrGS63 & $9.1 \mathrm{~cm}$ & 805 & $13.7 \mathrm{~cm}$ & 1233 & $26.1 \mathrm{~cm}$ & 2349 \\
\hline 2 & OrGS49 & $9.8 \mathrm{~cm}$ & 852 & $13.4 \mathrm{~cm}$ & 1192 & $22.5 \mathrm{~cm}$ & 2002 \\
\hline 4 & $\begin{array}{c}\text { Control } \\
\text { (uninoculated) }\end{array}$ & $4.5 \mathrm{~cm}$ & 337 & $7.3 \mathrm{~cm}$ & 547.5 & $10.5 \mathrm{~cm}$ & 787 \\
\hline
\end{tabular}

Fig.1 Pseudomonas strains under UV light

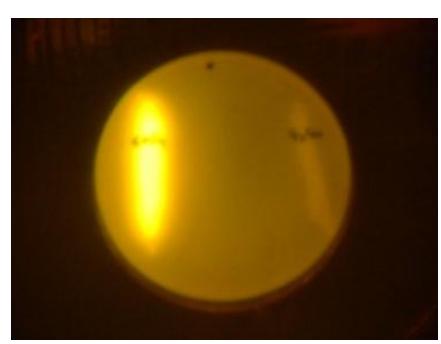

Fig.2 Pseudomonas strains on King B Agar Plates

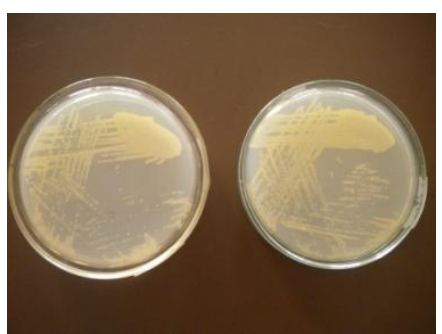

Fig.3 Siderophore production of Pseudomonas strains on CAS Agar plates showing pink color halo zone along with the control plate

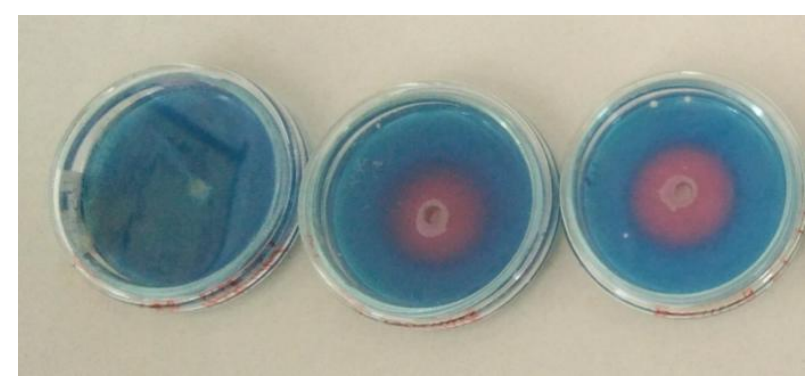


Fig.4 Phosphate solubilization

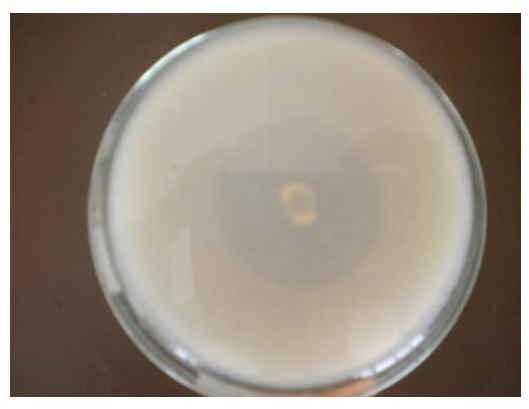

Fig.6 IAA production

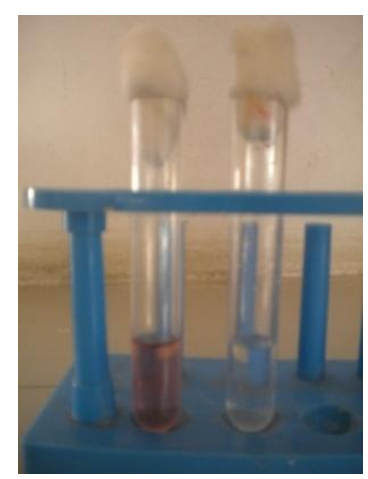

Fig.5 HCN Production

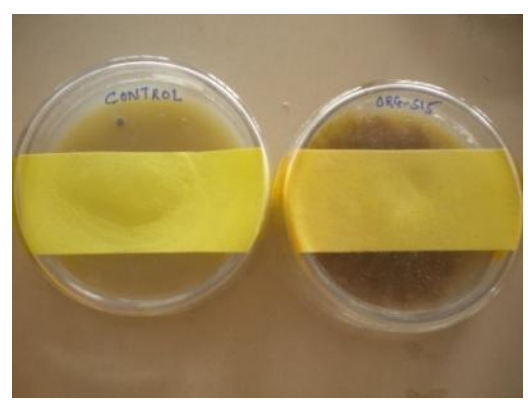

Fig.7 Ammonia Production

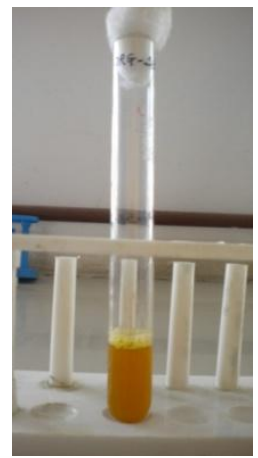

Fig.8 Antagonistic activity of Pseudomonas strains against Fusarium oxysporum
Control plate
Experimental Plate

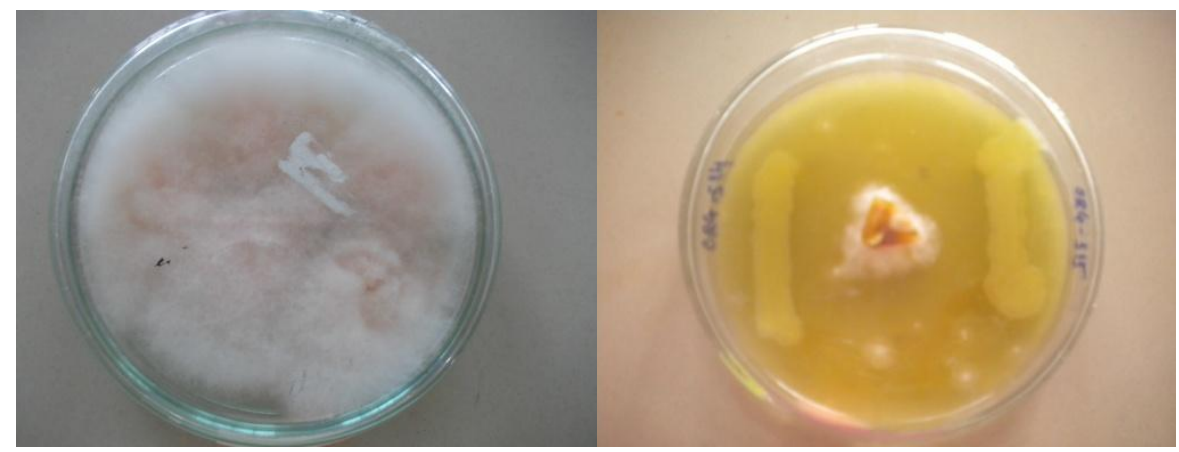


Fig.9 seedling growth along with Control

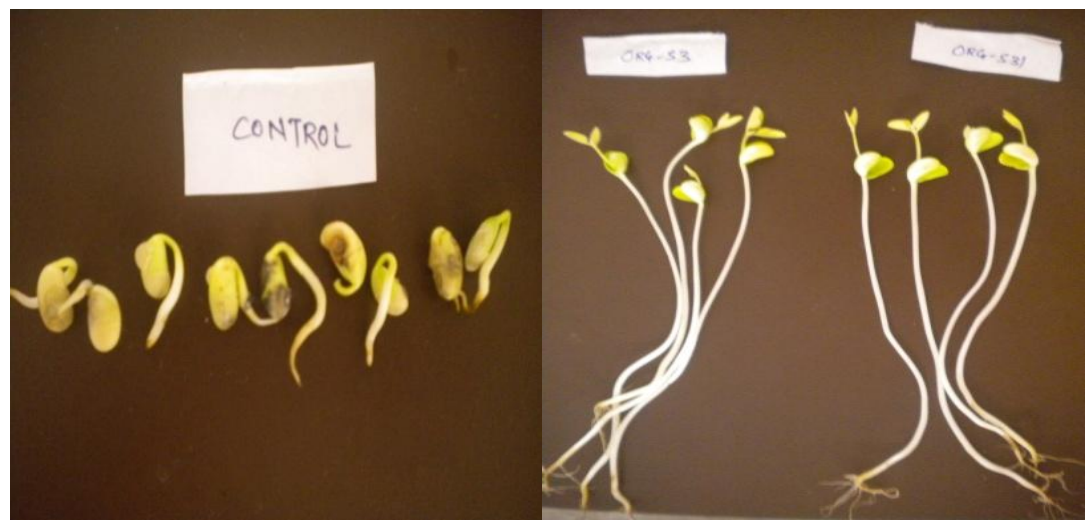

\section{References}

Yang X.B., Feng F. (2001): Ranges and diversity of soybean fungal diseases in North America. Phytopathology, 91: 769-775.

Szentes, S., Radu, G., Laslo, É., Lányi, S., and Mara, G. (2013). Selection and evaluation of potential biocontrol rhizobacteria from a raised bog environment. Crop Protection, 52, 116-124.

Naureen Z, Price AH, Hafeez FY, Roberts MR (2009) Identification of rice blast disease-suppressing bacterial strains from the rhizosphere of rice grown in Pakistan. Crop Prot 28: 1052-1060.

B.N.Johri, Alok Sharma and. "Growth Promoting Influence of siderophore prodcing Pseudomnas strains GRP3A and PRS9 in Maize (Zea mays L.)nder iron limiting condition." Microbial Research, 2003: 243-248.

Mardad, I., Serrano, A., and Soukri, A. (2013). Solubilization of inorganic phosphate and production of organic acids by bacteria isolated from a Moroccan mineral phosphate deposit, 7(8), 626635.

Walia, A., Mehta, P., Chauhan, A., and Shirkot, C. K. (2013). Antagonistic activity of plant growth promoting rhizobacteria isolated from tomato rhizosphere against soil borne fungal plant pathogens, 6(December), 571580

Y Singh, P.W.Ramteke and P K.Shukla. "Isolation and characterization of heavy metal resistant Pseudomonas spp. and their plant growth promotiong activities." Advances in Applied Science and Research 1 (4 2013): 269272.

Ganeshan, K. G., Archana, Y. L., and Rao, S. (2014). of Recent Scientific Effect of plant growth promoting rhizobacteria (PGPR) on germination, seedling growth and yield of tomato 1438 1437-1443.

\section{How to cite this article:}

Harshada S. Kitey and Vijay N. Charde. 2019. Pseudomonas fluorescens: A Proficient Plant Growth Promoting Rhizobacteria Isolated from Organic Farm. Int.J.Curr.Microbiol.App.Sci. 8(11): 1986-1991. doi: https://doi.org/10.20546/ijcmas.2019.811.232 